\title{
PENGARUH PENDIDIKAN KESEHATAN TERHADAP PERSONAL HYGIENE RAMBUT PADA ANAK USIA SEKOLA DASAR. \\ (Studi di SDN 3 Sidorejo Kel. Sidorejo Kec. Arut Selatan Kab. Kotawaringin Barat. Prov.Kalimantan Tengah Tahun 2017)
}

\author{
Putri Shinyin Tiarana ${ }^{1}$ Rahaju Ningtyas ${ }^{2}$ Rastia Ningsih $^{3}$ \\ ${ }^{123}$ STIKes Borneo Cendekia Medika Paagkalan Bun
}

1email : putrishinyin@gmail.com, 2email : ningtyasrahaju@ gmail.com, 3email : rastianingsih@gmail.com

\begin{abstract}
ABSTRAK
PendahuluanPersonal hygiene rambut adalah dimana perawatan rambut ini perlu perhatian lebih dan perlu tindak lebih lanjut pada anak usia sekolah dasar dengan lebih sering memberikan pendidikan kesehatan dan lebih menekankan kepada pihak sekolah. Tujuanpenelitian ini adalah untuk menganalisis tentang pengaruh pendidikan kesehatan terhadap personal hygiene rambut pada anak usia sekolah dasar di SDN 3 Sidorejo Pangkalanbun. Desain penelitian ini menggunakan metode pre eksperiment design dengan menggunakan pendekatan one group pretestposttest.Populasi pada penelitian ini adalahsiswa kelas V dan VI berjumlah 34 orang anak dengan menggunakan teknik total sampling. Teknik analisa data menggunakan uji Wilcoxon. Metode Pengumpulan data dengan tabulasi lembar observasi untuk variabel personal hygiene rambut. Personal hygiene rambut sebelum diberikan pendidikan kesehatan kurang bersih sebanyak 22 siswi (64.7\%), sedangkan personal hygiene rambut sesudah diberikan pendidikan kesehatan sebanyak 29 siswi (85,3\%). Hasil Dengan hasil uji wilcoxon 0,000 menunjukan nilai $\mathrm{p}<0,005$ menggunaka aplikasi spss 16.0. Kesimpulan Berdasarkan hal tersebut maka dapat disimpulkan bahwa terdapat pengaruh pendidikan kesehatan terhadap personal hygiene rambut pada anak usia sekolah dasar. Saran Bagi tenaga kesehatan,diharapkan beri penyuluhan,bagi tempat peneliti melakukan observasi lanjutan,bagi siswi mencuci rambut dengan teratur dan benar.
\end{abstract}

Kata kunci: Anak, pendidikan kesehatan, personal hygiene.

\section{THE EFFECT OF HEALTH EDUCATION ON HEALTH HYGIENE PERSONAL IN CHILDREN AGE OF BASIC SCHOOL.} (Study at SDN 3 Sidorejo Kel. Sidorejo South Arut Subdistrict of Kotawaringin BaratProvince, Central Kalimantan Province of 2017)

\section{ABSTRACT}

IntroductionPersonal hair hygiene is where these hair treatments need more attention and need further follow-up in primary school-aged children by more often providing health education and more emphasis to the school. The purpose of this study was to analyze the influence of health education on personal hair hygiene in elementary school age children at SDN 3 Sidorejo Pangkalanbun. This research design uses pre experiment design method using one group pretest-posttest 
approach. The population in this study are students of class V and VI amounted to 34 children using total sampling technique. Data analysis technique using Wilcoxon test. Methods Data collection with tabulation of observation sheet for personal hair hygiene variables. Personal hygiene before hair is given less clean health education as much as 22 students (64.7\%), while personal hair hygiene after being given health education as much as 29 female students (85.3\%). Result With wilcoxon 0.000 test result p value <0,55 using spss 16.0 application. Conclusion Based on this matter, it can be concluded that there is influence of health education on personal hair hygiene in elementary school age children. Suggestion For health workers, it is expected to give counseling, for the researcher to do follow-up observation, for students to wash hair regularly and correctly.

Keywords: Child, health education, personal hygiene.

\section{PENDAHULUAN}

Personal hygiene atau yang sering disebut dengan kebersihan diri adalah kegiatan dalam melakukan tindakan untuk menjaga kebersihan dirinya agar mendapat kebugaran fisik dan kesehatan yang berdampak pada dirinya sendiri dan mampu untuk menjaga kesehatannya dalam aktivitasnya sehari-hari.Personal hygiene (kebersihan diri)adalah kebersihan dan kesehatan perorangan yang bertujuan untuk mencegah timbulnya penyakit pada diri sendiri maupun orang lain (Tarwoto dan Wartonah 2006 dalam Nurjannah 2012,2) Salah satu bentuk personal hygiene adalah perawatan rambut dimana perawatan rambut ini dapat menjadi suatu indikator status kesehatan umum, perubahan hormonal, strees emosional fisik, penuaan, infeksi serta penyakit yang dapat mempengaruhi karakteristik rambut, dampak perawatan rambut secara fisik dapat berupa penampilan, kesejahteraan seseorang yang sering tergantung dengan penampilan rambutnya, karena rambut merupakan bagian tubuh yang memiliki fungsi sebagai proteksi serta pengatur suhu, dan melalu rambut perubahan status kesehatan diri dapat diidentifikasi. Dampak lain dari perawatan rambut adalah secara psikososial yang berakibat pada rasa nyaman, harga diri dan gangguan interaksi sosial (Ambarwati dan Sunarsih dalam Mustaghfiroh 2013,2).Rambut yang sehat terlihat mengkilau, tidak berminyak, tidak mudah kering dan tidak lembab sehingga kutu jarang untuk bersarang...Mencuci rambut dilakukan minimal 2 kali dalam seminggu (Mulyani dan Gracinia,2007 dalam Yuliyanti, et all, 2015, 2). Kutu rambut lebih banyak terdapat pada anak yang mencuci rambutnya satu kali dalam seminggu. Dibandingkan yang mencucinya lebih dari 3 kali dalam seminggu (AL-Basthtawy dan Hasna, 2012 dalam Yuliyanti, et all, 2015, 2).

prevalensi pedikulosis kapitis pada anak sekolah dasar di Amerika cukup tinggi yaitu $4.3 \%$ dari 24.000 murid di Arizona, 3\% dari 1,783 murid di Georgia, dan 7,2\% dari 2.650 murid di New York (Hadidjaja, 2011 didalam Yuliyanti, et all, 2015, 2). Prevalensi pedikulosis pada anak usia sekolah dasar di negara maju seperti Belgia adalah sebesar 8,9\%, sedangkan di negara 
berkembang prevalensi pedikulosis pada anak usia sekolah sebesar $16.59 \%$ di India, 58,9\% di Alexandria, Mesir, dan $81,9 \%$ di Argentina (Salim dan Linuwih, 2013 didalam Yuliyanti, et all, 2015, 2). Kejadain pedikulosis kapitis terjadi 92\% pada anak-anak daripada orang dewasa. Disebutkan pula bahwa anak perempuan lebih banyak terinfeksi pedikulosis kapitis dengan pravelensi $35,4 \%$ dibandingkan dengan anak laki-laki(Etim, 2012 didalam Yuliyanti, et all, 2015, 2). Anak perlu dilatih untuk mengurus dirinya sendiri sekaligus menjaga kebersihan diri, dimulai dari kegiatan yang sederhana salah satunya dengan mencuci rambut. Kebanyakan anakanak mencuci rambut sebagai bagian dari waktu mandi mereka. Peneliti belum menemukan data mengenai prevalensi seluruh anak usia sekolah di Indonesia, namun berdasarkan survei prevalensi pedikulosis kapitis pada murid kelas V dan VI di SD negeri kabupaten tanah datar, Sumatera Barat terdapat 51,92\% murid yang terinfeksi pedikulosis kapitis. Berdasarkan hasil studi pendahuluan yang dilakukan pada hari sabtu tanggal 18 Maret 2016 pada siswi kelas V dan VI di SDN 3 Sidorejo melalui pengamatan dengan cara melihat satu persatu siswi dari 10 siswi yang ada diambil seluruhnya untuk responden siswi dari responden yang diambil terdapat $10(100 \%)$ siswi yang punya kutu rambut (pedikulosiskapitis) dari $10(100 \%)$ yang terdapat kutuan hanya melakukan keramas $1 \mathrm{x}$ selama seminggu, sedangkan keramas yang normal ialah $2 \mathrm{x}$ seminggu.

Akibat dari pediculosis capitis dapat menimbulkan kelainan kulit kepala dan dapat menimbulkan infeksi sekunder bila digaruk(Hardiyanti 2015.2). Kutu juga dapat menyebabkan psikologis terganggu dan dapat menggangu kinerja belajar di sekolah (Mustafa Gulgun, 2013 dalam Yuliyanti, et all, 2015, 2). Jika kutu (Pediculosis kcapitis) terlalu dibiarkan dan tidak segera diobati dan dibiarkan bersarang pada waktu yang lama makan akan mengganggu kesehatan anak tersebut seperti akan menjadi koreng bahkan infeksi dikarenakan sering digaruk ketika gatal.

Untukmengatasi masalah kebersihan diri (personal hygiene) yang ada pada anak-anak sekolah dasar terutama pada rambut dengan masalah kutu ((Pediculosis kapitis) yang ada maka perlunya pendidikan kesehatan yang dilakukan tentang personal hygiene rambut di sekolah minimal 1 bulan sekali.Pendidikan kesehatan merupakan komponen dari program-program kesehatan dan kedokteran yang didalamnya termuat usaha-usaha yang terencana untuk merubah tingkah laku individu, kelompok dan masyarakat (apa yang dipikirkan, dirasakan dan dikerjakan) dengan tujuan menolongtercapainya tujuan

pengobatan,rehabilitasi,pencegahan penyakit dan peningkatan kesehatan (Guy Steuart dalam Siswanto, 2010, 38). Berdasarkan latar belakang diatas, penulis ingin meneliti tentang "Pengaruh Pendidikan Kesehatan Terhadap Personal Hygiene Rambut Pada Anak Sekolah Dasar Di SDN 3 Sidorejo" untuk mengetahui sejauh mana personal hygiene pada anak Sekolah Dasar SDN 3 Sidorejo dengan adanya pendidikan kesehatan yang akan diberikan. 


\section{METODE PENELITIAN}

Penelitian ini menggunakan metode pre eksperiment design dengan menggunakan pendekatan one group pretest-posttest design.Populasi penelitian ini adalah seluruh siswi kelas V dan di SDN 3 Sidorejo Kel. Sidorejo Kec. Arut Selatan Kab. Kotawaringin Barat. Prov. Kalimantan Tengah yang berjumlah 34 orang. Teknik pengambilan sampel yang digunakan adalah total sampling. Variabel independen penelitian ini adalah Pendidikan kesehatan dan dependen adalah personal hygiene rambut.Alat pengumpulan data adalah lembar observasi.Analisa data menggunakan uji Wilcoxon dengan $\alpha=0,05$.

\section{HASIL PENELITIAN}

\section{Data Umum}

Tabel 1 Distribusi Responden Berdasarkan Keramas di Kelas V dan VI DI SDN 3 Sidorejo pangkalanbun.

\begin{tabular}{cccc}
\hline No & Keramas & Jumlah & $\begin{array}{c}\text { Persentase } \\
(\%)\end{array}$ \\
\hline 1 & $1 \mathrm{x}$ & 1 & 2,9 \\
2 & $2-3 \mathrm{x}$ & 28 & 82,3 \\
3 & $>3 \mathrm{x}$ & 5 & 14,7 \\
\hline & Total & 34 & 100 \\
\hline
\end{tabular}

Dari tabel diatas diketahui hampir seluruhnya responden keramas 2-3x sejumlah 28 siswi $(82,3 \%)$.

Tabel 2 Distribusi Responden Berdasarkan membersihkan rambut di Kelas V dan VI di SDN 3 Sidorejo Pangkalan bun.

\begin{tabular}{cccc} 
No & $\begin{array}{c}\text { Membantu } \\
\text { Membersihkan } \\
\text { rambut }\end{array}$ & Jumlah & $\begin{array}{c}\text { Persentase } \\
(\%)\end{array}$ \\
\hline 1 & Ibu & 34 & 100 \\
2 & Ayah & 0 & 0 \\
3 & Kakak & 0 & 0 \\
\hline & Total & 34 & 100 \\
\hline
\end{tabular}

Sumber data primer 2017

Dari Tabel diatas diketahui bahwa responden seluruhnya paling banyak dibantu membersihkan rambut dengan ibu yaitu berjumlah 34 siswi (100\%).

Tabel 3 Distribusi Responden Berdasarkan perawatan alat rambut di Kelas V dan VI di SDN 3 Sidorejo Pangkalan bun

\begin{tabular}{|c|c|c|c|}
\hline No & $\begin{array}{c}\text { Perawatan alat } \\
\text { rambut }\end{array}$ & Jumlah & $\begin{array}{c}\text { Persentase } \\
(\%)\end{array}$ \\
\hline & $\begin{array}{l}\text { Mencuci barang } \\
\text { Menggantidengan }\end{array}$ & 19 & 55,8 \\
\hline 2 & yangbaru & 15 & 44,1 \\
\hline & Total & 34 & 100 \\
\hline
\end{tabular}

Dari tabel diatas diketahui bahwa sebagian besar dari responden dengan mencuci barang sekitar 19 siswi $(55,8 \%)$.

Tabel 4 Distribusi Responden Berdasarkan rambut tetap segar di kelas V dan VI di SDN 3 Sidorejo Pangkalan bun.

\begin{tabular}{|c|c|c|c|}
\hline No & $\begin{array}{l}\text { Rambut } \\
\text { tetap } \\
\text { segar }\end{array}$ & Jumlah & $\begin{array}{c}\text { Persentase } \\
(\%)\end{array}$ \\
\hline 1 & $\begin{array}{c}\text { Mencuci } \\
\text { rambut }\end{array}$ & 19 & 55,8 \\
\hline 2 & $\begin{array}{c}\text { Mengikat } \\
\text { rambut }\end{array}$ & 15 & 44,2 \\
\hline & Total & 34 & 100 \\
\hline
\end{tabular}

Dari Tabel diatas diketahui bahwa sebagian besar dari responden paling 
banyak rambut tetap segar dengan mencuci rambut sekitar 19 siswi $(55,8)$.

Tabel 5 Distribusi Responden Berdasarkan informasi membasmi kutu segar di kelas V dan VI di SDN 3 Sidorejo Pangkalan bun.

\begin{tabular}{cccc}
\hline No & $\begin{array}{c}\text { Membasmi } \\
\text { kutu }\end{array}$ & Jumlah & $\begin{array}{c}\text { Persentase } \\
(\%)\end{array}$ \\
\hline 1 & Pernah & 13 & 38,2 \\
& Tidak & & 61,7 \\
2 & pernah & 21 & \\
& & & \\
\hline & Total & 34 & 100 \\
\hline
\end{tabular}

Dari Tabel diatas diketahui bahwa sebagian besar dari responden tidak pernah membasmi kutu dengan jumlah sekitar 21 siswi $(61,7 \%)$.

Tabel 6 Distribusi Responden Berdasarkan cara membasmi kutu di kelas V dan VI di SDN 3 Sidorejo Pangkalan bun.

\begin{tabular}{cccc}
\hline No & $\begin{array}{c}\text { Cara } \\
\text { membasmi } \\
\text { kutu }\end{array}$ & Jumlah & $\begin{array}{c}\text { Persentase } \\
(\%)\end{array}$ \\
\hline 1 & Tahu & 15 & 44,1 \\
& & & 55,9 \\
2 & Tidak tahu & 19 & \\
& & & \\
\hline
\end{tabular}

\begin{tabular}{ccc}
\hline Total & 34 & 100 \\
\hline Sumber data primer 2017
\end{tabular}

Dari Tabel diatas diketahui bahwa responden sebagian besar dari responden yaitu Tidak tahu cara membasmi kutu dengan jumlah sekitar 19siswi $(55,9 \%)$.

Tabel 7Distribusi Responden Berdasarkan informasi kutu di kelas V dan VI di SDN 3 Sidorejo Pangkalan bun.

\begin{tabular}{|c|c|c|c|}
\hline No & $\begin{array}{c}\text { Informasi } \\
\text { kutu }\end{array}$ & Jumlah & $\begin{array}{c}\text { Persentase } \\
(\%)\end{array}$ \\
\hline \multirow[t]{2}{*}{1} & Pernah & 12 & 35,3 \\
\hline & Tidak & & 64,7 \\
\hline \multirow[t]{2}{*}{2} & Pernah & 22 & \\
\hline & Total & 34 & 100 \\
\hline
\end{tabular}

Dari Tabel diatas diketahui bahwa sebagian besar dari responden tidak pernah mendapat informasi kutu yaitu sebanyak 22 siswi $(64,7 \%)$

\section{Data Khusus}

Personal hygiene rambut siswa sebelum pendidikan kesehatan (Pretest)

Tabel 8 Distribusi Responden Berdasarkan personal hygiene rambut pada anak usia sekolah dasar di SDN 3 sidorejo pangkalan bun tahun 2017.

\begin{tabular}{|c|c|c|}
\hline $\begin{array}{c}\text { Personal } \\
\text { No hygiene } \\
\text { rambut }\end{array}$ & Jumlah & Persentase $(\%)$ \\
\hline 1. Bersih & 12 & 35,3 \\
\hline $\begin{array}{c}\text { 2. Kurang } \\
\text { bersih }\end{array}$ & 22 & 64,7 \\
\hline Total & 34 & 100 \\
\hline \multicolumn{3}{|c|}{ Sumber : Data Primer, 2017} \\
\hline \multicolumn{3}{|c|}{$\begin{array}{l}\text { Dari tabel sebelum dilakukan } \\
\text { pendidikan kesehatan diketahui } \\
\text { sebagian besar dari responden } \\
\text { dinyatakan personal hygiene rambut } \\
\text { kurang bersih yaitu sebanyak } 22 \text { siswi } \\
(64,7 \%) \text {. }\end{array}$} \\
\hline
\end{tabular}

Personal hygiene rambut siswa sesudah pendidikan kesehatan (Post test)

Tabel 9 Distribusi Responden Berdasarkan personal hygiene rambut pada anak usia sekolah dasar di sdn 3 sidorejo pangkalanbun tahun 2017. 


\begin{tabular}{|c|c|c|c|}
\hline No & $\begin{array}{l}\text { Personal } \\
\text { hygiene } \\
\text { rambut }\end{array}$ & Jumlah & Persentase $(\%)$ \\
\hline 1. & Bersih & 29 & 85,3 \\
\hline 2. & $\begin{array}{l}\text { Kurang } \\
\text { bersih }\end{array}$ & 5 & 14,7 \\
\hline & Total & 34 & 100 \\
\hline
\end{tabular}

Dari tabel setelah dilakukan pendidikan kesehatan diketahui hampir seluruhnya dari responden dinyatakan personal hygiene rambut bersih yaitu sebanyak 29 siswi $(85,3 \%)$.

\section{Hasil analisis pengaruh personal hygiene rambut}

Tabel 10 Tabulasi Responden Berdasarkan personal hygiene rambut Pre Post pada anak usia sekolah dasar di sdn 3 sidorejo pangkalanbun tahun 2017.

\begin{tabular}{|c|c|c|c|c|c|}
\hline \multirow[b]{2}{*}{ No } & \multirow{2}{*}{$\begin{array}{c}\text { Kategori } \\
\text { personal } \\
\text { hygiene } \\
\text { rambut }\end{array}$} & \multicolumn{2}{|c|}{ Sebelum } & \multicolumn{2}{|c|}{ Sesudah } \\
\hline & & Jumlah & $\%$ & lah & $\%$ \\
\hline 1 & Bersih & 12 & 35,3 & 29 & $\overline{85,3}$ \\
\hline 2 & $\begin{array}{l}\text { Kurang } \\
\text { bersih }\end{array}$ & 22 & 64,7 & 5 & 14,7 \\
\hline \multicolumn{6}{|c|}{ Uji Wilcoxon $\rho=0,000$} \\
\hline
\end{tabular}

Berdasarkan tabel didapat perubahan sebelum dan setelah diberikan pendidikan kesehatan yaitu sebesar 17 orang siswi (50\%)

Berdasarkan hasil penghitungan uji statistik wilcoxon diperoleh $\mathrm{p}$ value 0,000. jika $\alpha=0,05$ maka $\rho<\alpha$ dan H1 diterima, jadi ada pengaruh pendidikan kesehatan terhadap personal hygiene rambut pada anak usia sekolah dasar.

\section{PEMBAHASAN}

Setelah dilakukan analisis data dan menguji hasil penelitian dengan menggunakan uji statistik rankwilcoxon diperoleh hasil signifikan sebelum dan sesudah diberikan pendidikan kesehatan personal hygiene rambut cukup bervariasi sehingga memerlukan pembahasan tentang pengaruh pendidikan kesehatan terhadap personal hygiene rambut pada anak usia sekolah dasar.

\section{Personal hygiene rambut sebelum dilakukan pendidikan kesehatan}

Menurut hasil penelitian yang di tunjukkan pada tabel 8 menyatakan bahwa personal hygiene rambut siswi sebelum dilakukan penyuluhan tentang personal hygiene rambut dan membasmi kutu dengan kriteria kurang bersih berjumlah 22 siswi $(64,7 \%)$, hal itu dikarenakan kurangnya pengetahuan bagaimana cara membasmi kutu dan tidak pernah melakukan pembasmian kutu dilihat dari data yang ada yang tidak pernah membasmi kutu sebagian besar dari responden yang berjumlah 21 siswi $(61,7 \%)$,dan tidak tahu bagaiman cara membasmi kutu juga dengan responden sebanyak 19 siswi (55,9\%). Dan juga kurangnya informasi kutu dapat dilihat dari data yang ada sebanyak 22 siswi $(64,7 \%)$.

Personal hygiene rambut responden dipengaruhi oleh citra,praktik sosial,status

Sosial konomi,pengetahuan, variabel kebudayaan,kebiasaan seseorang dan kondisi fisik (Tarwoto dan Wartonah 2011,7)). Hal - hal diatas juga dipengaruhi beberapa faktor antara lain pengalaman pribadi, dan juga wawasan dari luar sehingga pengetahuan mereka dalam menjaga kebersihan rambut sangat kurang sehingga tentang kutu rambut (pedikulosis kapitis) jarang mereka dengar bahkan menurut mereka 
masalah kutu rambut tidak terlalu penting dan faktor faktor lain yang mempengaruhi seperti menjaga kebersihan rambut, seperti keramas yang baik itu berapa kali cara menjaga alat-alat rambut dengan baik dan bagaimana cara membasmi kutu rambut sehingga mempengaruhi mereka dalam pengetahuan tentang personal hygiene rambut.

Menurut peneliti kurangnnya pengetahuanpersonal hygiene rambut seseorang dikarenakan siswi kurang mengerti/tidak tahu tentang cara menjaga personal hygiene rambut serta kurangnya keterbukaan siswi pada orang tuanya tentang masalah yang dihadapinya terutama tentang personal hygiene rambut khusus nya masalah pada kutu rambut (pedikulosis kapitis).

\section{Personal hygiene rambut setelah dilakukan pendidikan kesehatan}

Berdasarkan table 9 pengaruh pendidikan kesehatan terhadap personal hygiene rambut pada anak usia sekolah dasar setelah dilakukan penyuluhan didapatkan hasil dengan kriteria bersih sebanyak sejumlah 29 siswi (85,3\%).Sesuai pernyataan apabila seseorang mengalami gangguan kesehatannya maka mereka akan mencari informasi sebanyak-banyaknya (Nasir, 2009,42).

Pendidikan kesehatan adalah suatu proses untukmemampukan masyarakat dalam memelihara dan meningkatkan kesehatan mereka (Notoatmodjo,2010,25).Tujuan dari pendidikan kesehatan adalah tercapainya perubahan perilaku,terbentuknya perilaku sehat,dan dapat mengubah perilaku hidup perseorangan (Effendy dan Makhfudli, 2007.8).Setelah responden diberi pendidikan kesehatan tentang personal hygiene rambut dan cara membasmi kutu mereka lebih mengerti tentang definisi, faktor yang mempengaruhi, tujuan,cara menjaga kebersihan rambut,cara penjegahan kutu rambut dan cara membasmi kutu rambut, sehingga mereka mengerti tentang materi yang diberikan oleh peneliti. Siswi yang mempunyai personal hygiene rambut bersih dikarenakan siswi mampu memahami arti dari personal hygiene rambut dan membasmi kutu tersebut. Setelah dilakukannya penyuluhan pendidikan kesehatan tentang personal hygiene rambut siswi mampu berfikir kritis sehingga dapat melakukan personal hygiene rambut dengan baik sehingga bersih. Diharapkan setelah penyuluhan ini maka akan tercipta personal hygiene rambut yang bersih dan cara membasmi kutu terhadap dirinya sendiri, yang dalam hal ini jika semakin tinggi tingkat pengetahuan tentang personal hygiene rambut maka akan semakin pula memperhatikan personal hygiene rambut pada dirinya terutama terhindar dari kutu. Hal ini disebabkan karena responden menerima dan tertarik dengan pendidikan kesehatan berupa penyuluhan dan dari video dan demonstarsi yang saya lakukan mereka ingin tahu ( know ) tentang apa itu kutu lebih jauh.

\section{Pengaruh pendidikan kesehatan terhadap personal hygiene rambut}

Berdasarkan tabel 10 menunjukkan pengaruh pendidikan kesehatan di tunjukkan dengan uji statistik wilcoxon dengan nilai signifikasi $\rho=0,000 \mathrm{Hal}$ ini dikarenakan tingkat pengetahuan respoonden yang baik. Peningkatan personal hygiene rambut dari kriteria kurang bersih menjadi kriteria 
bersih.Peningkatan ini tidak lepas adanya penyuluhan tentang personal hygiene rambut dan cara membasmi kutu rambut meningkatkan pengetahuan siswi tentang personal hygiene rambut dan kutu. Dapatkah kiranya dimengerti bahwa informasi yang diberikan melalui program penyuluhan kesehatan tentang personal hygiene rambut dan membasmi kutu telah direspon dengan baik oleh para responden. Tingginya respon mereka tidak lepas dari minat respon yang tinggi untuk mengetahui tentang personal hygiene rambut dan cara membasmi kutu. Sesuai (Nasir 2010.3) yang menyatakan bahwa informasi akan mudah diterima dan disimpan dalam memori seseorang jika informasi itu sudah menjadi kebutuhan yang sangat esensial baginya.

\section{KESIMPULAN DAN SARAN}

\section{Kesimpulan}

1. Personal hygiene rambut sebelum mendapatkan pendidikan kesehatan menunjukkan kriteria kurang bersih lebih banyak dari kriteria bersih

2. Personal hygiene rambut sesudah mendapatkan pendidikan kesehatan menunjukkan kriteria bersih lebih banyak dari kriteria kurang bersih.

3. Ada pengaruh pendidikan kesehatan tehadap personal hygiene rambut pada anak usia sekolah dasar.

\section{Saran}

Berdasarkan hasil penelitian kiranya

1. Bagi tenaga kesehatan

Memperhatikan kejadian masalah pada dirinya terutama tentang personal hygiene rambut seperti mencuci rambut dengan teratur.
2. Bagi tempat penelitian di SDN 3 Sidorejo

Diharapkan ada materi pembelajaran tentang personal hygiene rambut terutama tentang kutu rambut dan ini bias dilakukan oleh guru penjaskes untuk memberikan pengetahuan yang lebih dan melanjutka observasi kutu dan personal hygiene rambut siswa secara rutin.

3. Bagi siswi SDN 3 Sidorejo

Bagi siswi putri ditingkatkan keaktifan untuk mencegah timbulnya kutu rambut dan memperhatikan kejadian masalah pada dirinya terutama tentang personal hygiene rambut seperti mencuci rambut dengan teratur.

4. Peneliti selanjutnya

Melakukan penelitian tentang faktor lain yang berhubungan dengan personal hygiene rambut terutama apa faktor yang menyebabkan kutu rambut mudah muncul kembali dan apakah ada cara yang lain untuk membasmi kutu rambut dengan cepat.

\section{DAFTAR PUSTAKA}

Abdul Nasir dkk. 2009,Komunikasi dalam keperawatan teori dan aplikasi, jakarta:Salemba Medika

Effendy,Ferry dan Makhfudli, 2007. Keperawatan Kesehatan Komunitas :Teori danPraktek Dalam Keperawatan. Jakarta: Salemba Medika.

Hardiyanti dkk .2015.Penatalaksanaan Pediculosis Capitis. 
Mustaghifroh,A.2013. Studi Deskriptif Personal Hygiene Perawatan Rambut Pada Pasien Rawat Inap di Rs Roemani Semarang.

Notoatmodjo,2010. Promosi Kesehatan Teori dan Aplikasi.Rineka Cipta:Jakarta.

Nurjannah,Anna,2012.Personal hygiene Siswa Sekolah Dasar Negeri Jatunagor.

Siswanto,H.2010.Pendidikan Kesehatan Anak Usia Dini.Yogyakarta: Pustaka Rihama.

Tarwoto. 2011. "Kebutuhan Dasar Manusia”. Jakarta: Salemba Medika.

Yuliyanti, Etrine, et all. 2015. "Faktorfaktor yang Berhubungan dengan Kejadian Pedikulosis Kapitis ii SD Negeri Kertasari".STIKes Santo Borromeus. Diakses 13 juni 2017ejournal. stikesborromeus. ac. id/ file/ 53.pdf. 